\title{
Consideraciones generales sobre juicio en línea en el contencioso administrativo federal en México*
}

\section{General Considerations on the Online Judgment in the Federal Administrative Contentious in Mexico}

\author{
Marco Aurelio NúÑez CuÉ**
}

\section{Sumario}

Introducción. I. Qué es el juicio en línea. II. Normatividad aplicable. III. Definición de conceptos. IV. Elección de la vía. V. Demanda. VI. Expediente electrónico. VII. Clave de acceso, contraseña y firma electrónica avanzada. VIII. Acuse de recibo electrónico. IX. Actuaciones en el juicio en línea. X. Pruebas. XI. Pruebas diversas a las documentales. XII. Copias para traslado en el caso de terceros interesados. XIII. Notificaciones. XIV. Horas hábiles. XV. Obligaciones de las autoridades administrativas. XVI. Inaplicación de las reglas del juicio en línea en el recurso de revisión y en el juicio de amparo. XVII.
Interrupción del funcionamiento del sistema de justicia en línea. XVIII. La acumulación de juicios sustanciados en línea y en la vía tradicional.

\section{Resumen}

En el presente artículo, el autor aborda las cuestiones generales del Juicio en Línea en el contencioso administrativo federal mexicano, analizando la normatividad aplicable al mismo, así como los diversos conceptos informáticos y procesales que impactan en la promoción, sustanciación y resolución de esta novedosa forma de impartir justicia en México.

* DOI: https://doi.org/10.18601/16926722.n11.04

** Licenciado en derecho por el ITESO. Maestría en Juicio de amparo y Maestría en Fiscal por la Universidad del Valle de Atemajac, Campus Guadalajara. Doctor en Derecho por el Instituto Internacional del Derecho y del Estado. Profesor a nivel posgrado y licenciatura de la Universidad Panamericana, Campus Guadalajara y del ITESO. Coordinador de la Comisión de Derecho Fiscal de la Barra Mexicana, Colegio de Abogados, A.C., Capítulo Jalisco. Fue Secretario de Acuerdos de la Sala Regional del Caribe del otrora Tribunal Federal de Justicia Fiscal y Administrativa; Subdelegado Regional Occidente y Director General de Coordinación de Delegaciones Regionales de la Procuraduría de la Defensa del Contribuyente. Es Académico Numerario de la Academia Mexicana de Derecho Fiscal, A.C. y Miembro de Número del Colegio Nacional de Profesores e Investigadores de Derecho Fiscal y Finanzas Públicas, A.C.Correo-e: marcoaureliocue@gmail.com 
Palabras clave: Juicio en línea, Sistema Judicial en Línea, Boletín Jurisdiccional, Firma electrónica, Expediente Electrónico, Tecnologías de la Información y Comunicación-TIC.

Abstract: In this article the author addresses the general issues about the trial line in the litigious administrative federal Mexican, analyzing the applicable regulations to it, as well as the various procedural concepts that have an impact in the promotion, conduction and resolution of this innovative way of give justice in Mexico.

Keywords: Trial in line, Jurisdictional Bulletin, Electronic Signature, Electronic
Record, Information and Communication

Technology - ICT .

\section{Introducción}

Ante uno de los principales problemas que enfrenta el Tribunal Federal de Justicia Administrativa, como lo es el retraso en la impartición de justicia como consecuencia de la ampliación de su competencia material ${ }^{1}$, se llegó a considerar que el uso de las Tecnologías de la Información y Comunicación existentes en la actualidad podía permitir que los juicios tramitados ante dicho Tribunal se substanciaran con mayor rapidez, garantizando de esta forma que la impartición de justicia administrativa fuera rápida y expedita, como lo mandatan los artículos 17 de la

\footnotetext{
${ }^{1}$ La competencia material del Tribunal Federal de Justicia Administrativa no siempre ha sido la misma que actualmente conocemos, puesto que esta, con el paso de los años, ha evolucionado considerablemente; en sus inicios, en 1936, el referido órgano de justicia (llamado en aquella época Tribunal Fiscal de la Federación), tenía competencia exclusivamente fiscal, como así se desprende de la lectura al artículo 14 de la Ley de Justicia Fiscal, en el que se preveía que dicho tribunal conocería de los juicios que se iniciaran contra las resoluciones de la Secretaría de Hacienda y Crédito Público, de sus dependencias o de cualquier organismo fiscal autónomo, que determinara la existencia de un crédito fiscal, lo fijaran en cantidad líquida o se dieran las bases para su liquidación; contra resoluciones dictadas por autoridades dependientes del Poder Ejecutivo que contuvieran responsabilidades administrativas en materia fiscal; contra sanciones por infracciones a las leyes fiscales; contra resoluciones diversas que causaran agravio en materia fiscal (no reparable mediante recurso administrativo); contra el ejercicio de la facultad económico-coactiva; contra la negativa de la autoridad para devolver un impuesto, derecho o aprovechamiento ilegalmente percibido; asimismo, contaba con competencia para nulificar una resolución administrativa favorable a un particular, lo que hoy en día conocemos como juicio de lesividad. Sin embargo, actualmente dicha jurisdicción contencioso administrativa se ha convertido en un verdadero tribunal de justicia administrativa, a raíz de las diversas reformas legales que han sufrido tanto su Ley Orgánica como diversas leyes administrativas en la que se le ha conferido competencia eminentemente administrativa, lo cual, dicho sea de paso, provocó que mediante reformas a la Ley Orgánica del Tribunal Fiscal de la Federación, publicadas en el Diario Oficial de la Federación el 31 de diciembre de 2000, se cambiara por primera vez en su historia la denominación de Tribunal Fiscal de la Federación por la de Tribunal Federal de Justicia Fiscal y Administrativa y, recientemente, por segunda ocasión, se cambiara esta última por Tribunal Federal de Justicia Administrativa, con motivo tanto del decreto por el que se reforman, adicionan y derogan diversas disposiciones de la Constitución Política de los Estados Unidos Mexicanos, en materia de combate a la corrupción, publicado en el Diario Oficial de la Federación el 27 de mayo de 2015, como del diverso por el que se expide la Ley General del Sistema Nacional Anticorrupción; la Ley General de Responsabilidades Administrativas, y la Ley Orgánica del Tribunal Federal de Justicia Administrativa, publicado en el mismo medio de difusión del 18 de julio de 2016.
} 
Constitución Política de los Estados Unidos Mexicanos y 25 de la Convención Americana sobre Derechos Humanos ${ }^{2}$-de observancia obligatoria para el Estado mexicano-.

Por ello, el juicio en línea fue creado con la finalidad de hacer frente al rezago jurisdiccional que afecta al Tribunal Federal de Justicia Administrativa, y de garantizar a los justiciables el derecho humano de justicia pronta y expedita, utilizando para ello las Tecnologías de la Información y Comunicación.
El juicio en línea, se implementó en México, mediante el Decreto por el que se reforman y adicionan diversas disposiciones de la Ley Federal de Procedimiento Contencioso Administrativo y de la Ley Orgánica del Tribunal Federal de Justicia Fiscal y Administrativa, publicado en el Diario Oficial de la Federación el 12 de junio de $2009^{[3]}$. Mediante dicho decreto, se adicionó a la ley citada en primer término el Capítulo X, denominado "Del Juicio en Línea", incorporándose de esta forma no solo una nueva manera impugnar los actos administrativos

${ }^{2}$ El artículo 17 de la Constitución Política de los Estados Unidos Mexicanos dispone: "Ninguna persona podrá hacerse justicia por sí misma, ni ejercer violencia para reclamar su derecho. Toda persona tiene derecho a que se le administre justicia por tribunales que estarán expeditos para impartirla en los plazos y términos que fijen las leyes, emitiendo sus resoluciones de manera pronta, completa e imparcial. Su servicio será gratuito, quedando, en consecuencia, prohibidas las costas judiciales. Siempre que no se afecte la igualdad entre las partes, el debido proceso u otros derechos en los juicios o procedimientos seguidos en forma de juicio, las autoridades deberán privilegiar la solución del conflicto sobre los formalismos procedimentales. El Congreso de la Unión expedirá las leyes que regulen las acciones colectivas. Tales leyes determinarán las materias de aplicación, los procedimientos judiciales y los mecanismos de reparación del daño. Los jueces federales conocerán de forma exclusiva sobre estos procedimientos y mecanismos. Las leyes preverán mecanismos alternativos de solución de controversias. En la materia penal regularán su aplicación, asegurarán la reparación del daño y establecerán los casos en los que se requerirá supervisión judicial. Las sentencias que pongan fin a los procedimientos orales deberán ser explicadas en audiencia pública previa citación de las partes. Las leyes federales y locales establecerán los medios necesarios para que se garantice la independencia de los tribunales y la plena ejecución de sus resoluciones. La Federación y las entidades federativas garantizarán la existencia de un servicio de defensoría pública de calidad para la población y asegurarán las condiciones para un servicio profesional de carrera para los defensores. Las percepciones de los defensores no podrán ser inferiores a las que correspondan a los agentes del Ministerio Público. Nadie puede ser aprisionado por deudas de carácter puramente civil". El numeral 25 de la Convención Americana sobre Derechos Humanos, establece: "1. Toda persona tiene derecho a un recurso sencillo y rápido o a cualquier otro recurso efectivo ante los jueces o tribunales competentes, que la ampare contra actos que violen sus derechos fundamentales reconocidos por la Constitución, la ley o la presente Convención, aun cuando tal violación sea cometida por personas que actúen en ejercicio de sus funciones oficiales. 2. Los Estados Partes se comprometen: a) a garantizar que la autoridad competente prevista por el sistema legal del Estado decidirá sobre los derechos de toda persona que interponga tal recurso; b) a desarrollar las posibilidades de recurso judicial, y c) a garantizar el cumplimiento, por las autoridades competentes, de toda decisión en que se haya estimado procedente el recurso".

${ }^{3}$ El juicio en línea debió iniciar operaciones el día 13 de diciembre de 2010; sin embargo, el Artículo Tercero Transitorio del Decreto por el que se reforman, adicionan y derogan diversas disposiciones de la Ley Federal de Procedimiento Contencioso Administrativo y de la Ley Orgánica del Tribunal Federal de Justicia Fiscal y Administrativa, con las que se implementa el juicio contencioso administrativo federal en la vía sumaria -publicado en el Diario Oficial de la Federación el 10 de diciembre de 2010-, difirió su inicio de operaciones hasta el 7 de agosto de 2011, fecha en la cual también entraron en vigor la disposiciones relativas al juicio en la vía sumaria.

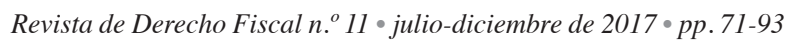


y fiscales federales, sino, además, una nueva forma de impartir justicia mediante el uso de las Tecnologías de la Información y Comunicación, específicamente a través de Internet.

\section{Qué es el juicio en línea}

El juicio en línea está definido por el artículo 1-A, fracción XIII, de la Ley Federal de Procedimiento Contencioso Administrativo, como la substanciación y resolución del juicio contencioso administrativo federal en todas sus etapas, así como de los procedimientos previstos en el artículo 58 de dicha ley (procedimientos para asegurar el pleno cumplimiento de las resoluciones del Tribunal), a través del Sistema de Justicia en Línea, incluso en los casos en que sea procedente la vía sumaria.

El concepto de juicio en línea suele confundirse con el de Sistema de Justicia en Línea, cuando son dos cuestiones totalmente distintas, ya que el primero se tramita precisamente en el segundo, es decir, el juicio en línea se tramita a través del Sistema de Justicia en Línea, siendo este, según lo señala el artículo 1-A, fracción XV, del invocado cuerpo de leyes, un sistema informático establecido por el Tribunal Federal de Justicia Administrativa, a efecto de registrar, controlar, procesar, almacenar, difundir, transmitir, gestionar, administrar y notificar el procedimiento contencioso administrativo que se sustancie ante dicho órgano de justicia.

En virtud de lo anterior, “(...) cuando se habla de justicia en línea se alude a una plataforma tecnológica en operación en el Tribunal en la que se puede tramitar el juicio contencioso administrativo federal en sus dos variantes: a) En la vía tradicional, en la que el juicio puede ser ordinario o sumario; b) En línea, en la que también el juicio puede ser ordinario o sumario" (Irigoyen Urdapilleta, 2012, p. 3).

A su vez, el Sistema de Justicia en Línea está compuesto de los siguientes tres subsistemas:

1) Subsistema de juicio tradicional, que permitirá controlar procesalmente el juicio contencioso administrativo federal en la citada vía tradicional; 2) Subsistema de juicio en línea, que permitirá la tramitación del juicio contencioso administrativo usando Internet, y, 3) Subsistema de información estadística, que consiste en la compilación del conocimiento institucional, ya sea jurisdiccional (mediante el módulo que integra este subsistema denominado "Banco de sentencias y criterios relevantes") o eminentemente estadístico (a través del módulo que también forma parte de este subsistema llamado "Indicadores de Gestión y Reportes de Operación”) (ibídem).

\section{Normatividad aplicable}

El juicio contencioso administrativo federal en línea o simplemente juicio en línea, está regulado en la Ley Federal de Procedimiento Contencioso Administrativo, específicamente en su Capítulo X, denominado "Del Juicio en Línea", y también en el Acuerdo E/JGA/16/2011, publicado en el Diario Oficial de la Federación el 4 de mayo de 2011, que establece los Lineamientos Técnicos y Formales para la Sustanciación del Juicio en Línea, emitido por la Junta de Gobierno y Administración del otrora Tribunal Federal de Justicia Fiscal y Administrativa, a través de su Presidente, en ejercicio de 
las atribuciones que le otorgaba el artículo 41, fracciones I, XXII, XXIV, XXX y XXXI de la extinta Ley Orgánica del Tribunal Federal de Justicia Fiscal y Administrativa, y con fundamento en los artículos 58-D y 58-E de la Ley Federal de Procedimiento Contencioso Administrativo.

Los referidos Lineamientos tienen por objeto establecer el procedimiento para el acceso y utilización del Sistema de Justicia en Línea, para la promoción, sustanciación y resolución del juicio en línea, y establecer las normas de carácter administrativo a las que deberán sujetarse los servidores públicos del Tribunal en el ejercicio de sus funciones jurisdiccionales, así como todos aquellos usuarios y administradores del sistema, que hagan uso del mismo. De manera que, para estos últimos, son de carácter general y de observancia obligatoria.

\section{Definición de conceptos}

Para entender mejor el funcionamiento del juicio en línea es necesario conocer diversos conceptos que se encuentran íntimamente relacionados con el mismo, los cuales están contenidos en el artículo 1-A de la Ley Federal de Procedimiento Contencioso Administrativo y en el artículo $2^{\circ}$ del Acuerdo E/ JGA/16/2011, y son los siguientes:

\section{Acuse de Recibo Electrónico: Constancia que acredita que un documento digital fue recibido por el Tribunal y estará sujeto a la misma regulación aplicable al uso de una firma electrónica avanzada. En este caso, el acuse de recibo electrónico identificará a la Sala que recibió el documento y se pre- sumirá, salvo prueba en contrario, que el documento digital fue recibido en la fecha y}

hora que se consignen en dicha constancia. El Tribunal establecerá los medios para que las partes y los autorizados para recibir notificaciones puedan verificar la autenticidad de los acuses de recibo electrónico.

II. Archivo Electrónico: Información contenida en texto, imagen, audio o video generada, enviada, recibida o archivada por medios electrónicos, ópticos o de cualquier otra tecnología que forma parte del Expediente Electrónico.

III. Boletín Jurisdiccional: Medio de comunicación oficial electrónico, a través del cual el Tribunal da a conocer las actuaciones o resoluciones en los juicios contenciosos administrativos federales que se tramitan ante el mismo.

III Bis. Aviso electrónico: Mensaje enviado a la dirección de correo electrónico de las partes de que se realizará una notificación por Boletín Jurisdiccional.

IV. Clave de acceso: Conjunto único de caracteres alfanuméricos asignados por el Sistema de Justicia en Línea del Tribunal a las partes, como medio de identificación de las personas facultadas en el juicio en que promuevan para utilizar el Sistema, y asignarles los privilegios de consulta del expediente respectivo o envío vía electrónica de promociones relativas a las actuaciones procesales con el uso de la firma electrónica avanzada en un procedimiento contencioso administrativo.

V. Contraseña: Conjunto único de caracteres alfanuméricos, asignados de manera confidencial por el Sistema de Justicia en Línea del Tribunal a los usuarios, la cual permite 
validar la identificación de la persona a la que se le asignó una Clave de Acceso.

VI. Dirección de Correo Electrónico: Sistema de comunicación a través de redes informáticas, señalado por las partes en el juicio contencioso administrativo federal.

VII. Dirección de Correo Electrónico Institucional: Sistema de comunicación a través de redes informáticas, dentro del dominio definido y proporcionado por los órganos gubernamentales a los servidores públicos.

VIII. Documento Electrónico o Digital: Todo mensaje de datos que contiene texto o escritura generada, enviada, recibida o archivada por medios electrónicos, ópticos o de cualquier otra tecnología que forma parte del Expediente Electrónico.

IX. Expediente Electrónico: Conjunto de información contenida en archivos electrónicos o documentos digitales que conforman un juicio contencioso administrativo federal, independientemente de que sea texto, imagen, audio o video, identificado por un número específico.

X. Firma Electrónica Avanzada: Conjunto de datos consignados en un mensaje electrónico adjuntados o lógicamente asociados al mismo que permita identificar a su autor mediante el Sistema de Justicia en línea, y que produce los mismos efectos jurídicos que la firma autógrafa. La firma electrónica permite actuar en juicio en línea.

XI. Juicio en la vía tradicional: El juicio contencioso administrativo federal que se substancia recibiendo las promociones y demás documentales en manuscrito o impresos en papel, y formando un expediente también en papel, donde se agregan las actuaciones procesales, incluso en los casos en que sea procedente la vía sumaria.

XII. Administrador: Servidor público del Tribunal, responsable de vigilar el cumplimiento de la normatividad relativa a la operación del Sistema, así como del mantenimiento del mismo.

XIII. Archivo administrativo: Conjunto organizado de documentos, en cualquier medio, físico o electrónico, que sean recibidos o producidos por las Unidades Administrativas del Tribunal o bien, por cualquier otra Unidad en el ejercicio de sus funciones o actividades de índole administrativa, distintas de las jurisdiccionales.

XIV. Centro de Atención a Usuarios: Oficina del Tribunal adscrita a la Unidad de Administración, encargada de atender dudas y asesorar a los Usuarios respecto del uso del Sistema, en coordinación con la Dirección.

XV. Código de Barras: Técnica de entrada de datos (tal como la captura manual, el reconocimiento óptico y la cinta magnética), con imágenes formadas por combinaciones de barras y espacios paralelos, de anchos variables. Representan números que a su vez pueden ser leídos y descifrados por lectores ópticos o escáners.

XVI. Correo Spam: Son mensajes no solicitados, no deseados, no esperados o de remitentes desconocidos, habitualmente de tipo publicitario enviados en cantidades masivas, generalmente por correo electrónico, cuyo objetivo es realizar un daño o 
un uso indebido de los medios y servicios disponibles por parte del Tribunal.

XVII. Datos personales: Información concerniente a la persona física identificada o identificable, relativa a su nombre, registro federal de contribuyentes, domicilio, número telefónico, correo electrónico personal, clave única de registro de población u otras análogas que afecten su intimidad.

XVIII. Depuración: Desintegración material de documentos y/o transferencia de documentos electrónicos a un medio secundario a fin de liberar espacio en el Sistema.

XIX. Dirección: Dirección General de Informática adscrita a la Secretaría Técnica Ejecutiva, cuyas atribuciones se describen en el artículo 87 del Reglamento Interior del Tribunal Federal de Justicia Fiscal y Administrativa.

XX. Documentos: Los expedientes, dictámenes, estudios, actas, resoluciones, constancias, oficios, correspondencia, acuerdos, circulares, contratos, convenios, instructivos, notas, memoranda, estadísticas o bien, cualquier otro registro que compruebe el ejercicio de las facultades o la actividad de las áreas jurisdiccionales o unidades administrativas, sin importar su fuente o fecha de elaboración. Los documentos podrán constar en cualquier medio, sea escrito, impreso, sonoro, visual, electrónico, informático, holográfico o cualquier otro derivado de la innovación tecnológica.

XXI. Huella Digital: Es la forma caprichosa que adopta la piel que cubre las yemas de los dedos. Está constituida por rugosidades que forman salientes y depresiones.
XXII. Información: Datos contenidos en los documentos o archivos que el Tribunal genere, obtenga, adquiera, transforme o conserve por cualquier título, en papel o medio electrónico.

XXIII. Internet: Conjunto de redes de comunicación interconectadas cuya finalidad es intercambiar información entre computadoras que se encuentran físicamente distantes.

XXIV. Intranet: Red de computadoras diseñada, desarrollada y administrada por el Tribunal, siguiendo los protocolos propios de Internet. Cuyo propósito es poner a disposición exclusiva de los servidores públicos del Tribunal, recursos, sistemas o información para su uso o aprovechamiento.

XXV. Módulo de Registro: Lugar en el que se lleva a cabo el registro de los Usuarios del Sistema, ubicado en cada una de las sedes del País en las que existen Salas Regionales del Tribunal.

XXVI. Unidad de Administración: La Unidad de Administración del Tribunal encargada de administrar y coordinar la operación del Sistema.

XXVII. Usuarios: Los usuarios externos e internos del Sistema.

XXVIII. Usuario Externo: Cualquier persona que, sin actuar como servidor púbico del Tribunal en funciones, sea parte en el juicio en línea y utilice el Sistema conforme a lo establecido en la Ley.

XXIX. Usuario Interno: Servidor público del Tribunal que por su perfil, ámbito de competencia y demás cuestiones relativas a 
la función que desempeña, requiera utilizar o administrar el Sistema.

XXX. Sistema: Sistema de Justicia en Línea.

XXXI. Virus: Es un programa o aplicación que tiene por objeto alterar o dañar el funcionamiento de una computadora, sistema o información, sin el permiso o el conocimiento del usuario.

\section{Elección de la vía}

El juicio en línea es optativo, únicamente para los particulares, por lo que cuando estos ejercen su derecho de presentar la demanda en línea, las autoridades administrativas demandadas están obligadas a comparecer y tramitar el juicio en la misma vía. Sin que suceda lo mismo cuando el demandante sea una autoridad (en el caso del juicio de lesividad), puesto que el particular demandado, al contestar la demanda, tiene la opción de tramitar el juicio en línea o de seguirlo en la vía tradicional, esto es, mediante promociones y demás documentales en manuscrito o impresos en papel; y ello se explica en razón de que, a nuestro parecer, no podría obligarse a los justiciables a tramitar un juicio a través de internet, puesto que ello sería violatorio del derecho fundamental de tutela judicial efectiva que consagran los artículos 17 constitucional y 25 de la Convención Americana sobre Derechos Humanos.

Cuando el demandante sea una autoridad, a fin de emplazar al particular demandado, el Secretario de Acuerdos al que corresponda, imprimirá y certificará la demanda y sus anexos que se notificarán de manera personal. Si el particular rechaza tramitar el juicio en línea contestará la demanda mediante el juicio en la vía tradicional.

\section{Demanda}

En el juicio contencioso administrativo federal, la demanda podrá presentarse a través de dos formas: por escrito ante la sala regional competente mediante el juicio en la vía tradicional o, en línea, a través del Sistema de Justicia en Línea; para este último supuesto, el demandante deberá manifestar su opción al momento de presentar la demanda. En caso de que no haga esa manifestación, se entenderá que eligió tramitar el juicio en la vía tradicional. Una vez elegida la opción, no podrá variarse.

En ese sentido, es claro que el demandante tiene el derecho de elegir si el juicio lo promueve en la vía tradicional o en línea, debiendo manifestar su decisión al momento de presentar la demanda, y en el caso de que no haga esa manifestación se entenderá que eligió tramitar el juicio en la vía tradicional.

Lo anterior, ha generado dudas tanto entre los litigantes como entre los magistrados del propio Tribunal Federal de Justicia Administrativa, puesto que hay quien opina que el demandante que presente su demanda en la vía tradicional (en papel) tiene la opción de señalar en ella que es su deseo tramitarla en línea, lo cual se considera incorrecto; al respecto, el ex Presidente del referido Tribunal, Juan Manuel Jiménez Illescas, en su obra El juicio en Línea. Procedimiento Contencioso Administrativo Federal, considera que “(...) se entiende que habiendo presentado la demanda en la forma tradicional, también se podrá manifestar por ese conducto la opción de seguir el Juicio en Línea, y si no se hace 
se deberá continuar en la vía tradicional..." (Jiménez Illescas, 2009, p. 65).

Desde un punto de vista jurídico, no es posible que el demandante, habiendo presentado la demanda en la forma tradicional, pueda manifestar por ese conducto la opción de seguir el juicio en línea, ni a la inversa, toda vez que el artículo 35 de los Lineamientos Técnicos y Formales para la Sustanciación del Juicio en Línea (Acuerdo E/JGA/16/2011), publicados en el Diario Oficial de la Federación el 4 de mayo de 2011 (de observancia obligatoria para todos los usuarios del Sistema de Justicia en Línea, conforme a lo previsto en su artículo $1^{\circ}$ ), se entenderá que el demandante opta por el juicio en línea cuando acceda al sistema y exprese su voluntad en ese sentido requisitando los campos de información correspondientes. La opción elegida no variará aunque en fecha posterior se presente una demanda en la vía tradicional, contra la misma resolución.

En razón de lo anterior, es claro que si el demandante presenta su demanda por escrito ante la Sala Regional competente, está optando por la vía tradicional; por lo contrario, si accede al sistema para presentar su demanda, es más que evidente que optó por tramitar el juicio en línea.

Por ello, “(...) en el supuesto de que se presente una demanda -en papel- ante una Sala Regional y se manifieste que se elige la vía en línea, el Magistrado instructor puede válidamente tramitar el juicio en la vía tradicional, porque el justiciable no ejerció su opción en línea correctamente toda vez que para seguir el juicio en dicha vía el actor debió ingresar al sistema y a través de él in- terponer su demanda, ya que expresamente así lo establece el numeral 13 de la LFPCA" (Irigoyen Urdapilleta, op. cit., nota 3, p. 6).

Cuando la autoridad tenga el carácter de demandante (tratándose del juicio de lesividad), la demanda se presentará en todos los casos en línea, a través del Sistema de Justicia en Línea.

\section{Expediente}

Así como en la vía tradicional existe un expediente físico o en papel, tratándose del juicio en línea existe un expediente electrónico, el cual se integra con el conjunto de información contenida en archivos electrónicos o documentos digitales; en dicho expediente se incluyen todas las promociones, pruebas y otros anexos que presenten las partes, oficios, acuerdos y resoluciones tanto interlocutorias como definitivas, así como las demás actuaciones que deriven de la substanciación del juicio en línea.

Se podría afirmar que uno de los temores que los justiciables, y principalmente los abogados litigantes, quienes manifiestan, en relación con la promoción del juicio en línea, es el atinente a la seguridad del expediente electrónico; al respecto, en la Ley Federal de Procedimiento Contencioso Administrativo, se señala que el Tribunal Federal de Justicia Administrativa deberá garantizar la seguridad, inalterabilidad, autenticidad, integridad y durabilidad del expediente electrónico conforme a los lineamientos que para tal efecto emita dicho Tribunal.

Sobre este aspecto, el artículo 11 de los Lineamientos Técnicos y Formales para la 
Sustanciación del Juicio en Línea, dispone lo siguiente:

El Magistrado Instructor en un Juicio en Línea que haya sido modificado, alterado, destruido o que haya sufrido pérdida de la información contenida en el Expediente Electrónico correspondiente, solicitará un reporte al titular de la Unidad de Administración responsable del Sistema sobre la irregularidad advertida.

Con base en el reporte de referencia, si el Usuario Externo que sea parte en el juicio en el que se hayan cometido las conductas señaladas en el párrafo anterior es el responsable, el Magistrado Instructor ordenará la cancelación de su Clave de Acceso y Contraseña, y acordará lo conducente a fin de que el juicio afectado se siga tramitando en la vía tradicional.

No se cancelará la Clave de Acceso y Contraseña cuando se surtan los supuestos del primer párrafo de este artículo y el o los responsables sean autoridades; no obstante lo anterior, el Tribunal presentará las denuncias correspondientes para que se inicien los procedimientos en materia de responsabilidades administrativas a los servidores públicos responsables, sin perjuicio de ejercer cualquier otra acción legal que proceda en su contra.

Las determinaciones que se tomen en términos del presente artículo, se darán a conocer a las Salas del Tribunal que tengan radicados juicios en línea, en los que intervenga la persona responsable, para que procedan en términos del artículo 58-R primer párrafo de la Ley, observando lo dispuesto en el Capítulo v, "De la Digitalización, Im- presión y Resguardo de Documentos", del

Título Sexto de los presentes Lineamientos.

Adicionalmente, a las sanciones que se prevén para los usuarios externos del sistema de justicia en línea, el artículo 58-R de la ley de la materia prevé como sanciones en caso de que el Tribunal advierta que alguna persona modificó, alteró, destruyó o provocó la pérdida de información contenida en el Sistema de Justicia en Línea, la cancelación de la firma electrónica avanzada; la imposibilidad de volver a promover juicios en línea; multa de trescientas a quinientas veces el salario mínimo general vigente en el Distrito Federal al momento de cometer la infracción y las responsabilidades penales que correspondan.

Se estima incorrecto que la ley establezca como sanción adicional que el Tribunal cancele la firma electrónica avanzada del particular, toda vez que no debe perderse de vista, por un lado, porque esta es proporcionada por el Servicio de Administración Tributaria y no por el Tribunal Federal de Justicia Administrativa (no obstante que el artículo 58-E de la Ley Federal de Procedimiento Contencioso Administrativo disponga que la firma electrónica avanzada, se proporcionará a través del Sistema de Justicia en Línea del Tribunal) y, por el otro, porque el uso de la aludida firma por parte de los contribuyentes no solo está destinado al juicio en línea, sino también, a diversos trámites que estos realizan ante la administración tributaria.

\section{Clave de acceso, contraseña y firma electrónica avanzada}

En el juicio en línea, con la finalidad de garantizar la seguridad del expediente electró- 
nico, únicamente tendrán acceso al mismo, exclusivamente para su consulta, las partes, las personas autorizadas y los delegados designados por las autoridades; claro está, una vez tengan registradas su clave de acceso y contraseña, las cuales se proporcionarán a través del Sistema de Justicia en Línea, previa obtención del registro y autorización correspondientes.

Al respecto, el Acuerdo E/JGA/16/2011 señala que las claves de acceso asignadas por el Sistema de Justicia en Línea a usuarios externos serán otorgadas exclusivamente a personas físicas, sean promoventes, autorizados, delegados, representantes legales, terceros interesados, peritos de las partes, peritos terceros, ciudadanos en general, así como aquellas personas físicas que ostenten la calidad de titular de una unidad administrativa, tanto susceptibles de ser actoras o demandadas, como las encargadas de su defensa jurídica.

Para que un usuario externo pueda obtener su clave de acceso y contraseña, es necesario que se apersone en el Módulo de Registro ubicado en la Sala Regional correspondiente, y cumpla con los siguientes requisitos:

I. Llenar la solicitud para obtener la clave de acceso y generar la contraseña, disponible en cada módulo de registro;

II. Proporcionar su nombre completo;

III. Precisar su domicilio (calle, número exterior e interior, calles que la circundan, colonia, ciudad, código postal, delegación o municipio, entidad federativa y país);

IV. Proporcionar su correo electrónico particular o institucional, en su caso;
V. Indicar su Clave Única de Registro de Población (CURP) siempre que se trate de personas físicas de nacionalidad mexicana;

VI. Precisar su nacionalidad;

VII. Exhibir su identificación oficial, y

VIII. Presentar el documento certificado con el que acredite su personalidad, cuando el trámite lo realice en representación de otra persona física.

Puede ser aceptada como identificación oficial cualquiera de los siguientes documentos:

I. Pasaporte vigente expedido por la Secretaría de Relaciones Exteriores;

II. Credencial para votar vigente expedida por el Instituto Federal Electoral;

III. Cédula profesional expedida por la Secretaría de Educación Pública;

IV. Cartilla del Servicio Militar Nacional, expedida por la Secretaría de la Defensa Nacional;

$V$. Tratándose de extranjeros, el documento migratorio vigente que corresponda, emitido por la autoridad competente;

VI. Visa emitida por el consulado o embajada, $y$

VII. Certificado de Matrícula Consular, expedido por la Secretaría de Relaciones Exteriores o en su caso por la Oficina Consular de la circunscripción donde se encuentre el connacional. 
Es importante señalar que el registro de la clave de acceso y contraseña implica el consentimiento expreso de que el Sistema de Justicia en Línea registre la fecha y hora en la que se abran los archivos electrónicos, que contengan las constancias que integran el expediente electrónico, para los efectos legales previstos en la Ley Federal de Procedimiento Contencioso Administrativo.

Además de ello, se destaca que quienes sean titulares de una clave de acceso y contraseña son responsables de su uso, por lo que el acceso o recepción de las notificaciones, la consulta al expediente electrónico y el envío de información mediante la utilización de cualquiera de dichos instrumentos, les serán atribuibles y no admitirán prueba en contrario, excepto cuando se demuestren fallas en el Sistema de Justicia en Línea.

De ahí que las personas que sean titulares de una clave de acceso y contraseña deberán suscribir una carta de conocimiento de dicha responsabilidad al momento de obtener dichos instrumentos.

Respecto a la firma electrónica avanzada, debemos reiterar que aunque en la ley de la materia se señale expresamente, que esta se proporcionará a través del Sistema de Justicia en Línea, ello es inexacto, puesto que, como hemos visto con antelación, dicha firma es proporcionada por el Servicio de Administración Tributaria.

De igual forma sucede para el caso de la clave de acceso y contraseña, ya que el registro de la firma electrónica avanzada implica el consentimiento expreso que el Sistema de Justicia en Línea registre la fecha y hora en la que se abran los archivos elec- trónicos, que contengan las constancias que integran el expediente electrónico, para los efectos legales establecidos en la ley de la materia.

Es importante mencionar que el 11 de enero de 2012 fue publicada en el Diario Oficial de la Federación la Ley de Firma Electrónica Avanzada, aunque por raro que llegue a parecer, no tiene absolutamente nada que ver con la firma electrónica avanzada que se utiliza en el juicio en línea, por la cual, se insiste, es la misma que utilizan los contribuyentes para realizar sus trámites ante el Servicio de Administración Tributaria.

La aseveración anterior se hace en virtud de lo señalado en el artículo 4 de la Ley de Firma Electrónica Avanzada, en el sentido de que las disposiciones de esa ley no serán aplicables a las materias fiscal, aduanera y financiera.

La importancia de la firma electrónica avanzada en el juicio en línea radica en que es la única herramienta con que cuenta el justiciable para actuar en dicho juicio, produciendo con su uso el mismo valor probatorio y efectos legales que la firma autógrafa en un juicio tradicional, permitiendo también garantizar la integridad de un documento.

Además de ello, según lo disponen los Lineamientos Técnicos y Formales para la Sustanciación del Juicio en Línea, la firma electrónica avanzada vincula y responsabiliza al promovente con el contenido de un documento electrónico presentado a través del Sistema de Justicia en Línea, de la misma forma en que la firma autógrafa lo hace respecto del documento que la contiene en un juicio tradicional. 
También debe decirse que, de conformidad con lo dispuesto en el artículo 30 de los aludidos Lineamientos, el uso de la firma electrónica avanzada implica:

I. La vinculación indubitable entre el firmante y el documento electrónico en el que se contenga la firma electrónica avanzada, que se asocia con los datos que se encuentran bajo el control exclusivo del firmante y que expresan en medio digital su identidad.

II. La responsabilidad de prevenir cualquier modificación o alteración en el contenido de los documentos electrónicos que se presentan en el Sistema, al existir un control exclusivo de los medios para insertar la referida firma, $y$

III. La integridad y autenticidad del contenido del documento firmado electrónicamente.

De la misma manera que sucede tratándose de la clave de acceso y contraseña, quienes sean titulares de una firma electrónica avanzada son responsables de su uso, por lo que el acceso o recepción de las notificaciones, la consulta al expediente electrónico y el envío de información mediante su utilización, les serán atribuibles y no admitirán prueba en contrario, excepto cuando se demuestren fallas en el Sistema de Justicia en Línea.

No siendo suficiente, los titulares de una firma electrónica avanzada tienen las siguientes obligaciones:

I. Resguardar la confidencialidad de la clave privada que se requiere para signar electrónicamente los documentos;
II. Mantener el control físico, personal y exclusivo de su Firma Electrónica Avanzada;

III. Actualizar los datos proporcionados para su tramitación, y

IV. Informar de manera inmediata al prestador de servicios de certificación, de cualquier circunstancia que ponga en riesgo su privacidad o confidencialidad en su uso, a fin de que, de ser necesario, se revoque.

\section{Acuse de recibo electrónico}

El acuse de recibo electrónico es la constancia que acredita que un documento digital fue recibido por el Tribunal Federal de Justicia Administrativa y está sujeto a la misma regulación aplicable al uso de una firma electrónica avanzada.

Salvo prueba en contrario, las promociones se considerarán presentadas el día y hora que conste en el acuse de recibo electrónico que emita el Sistema de Justicia en Línea, en el lugar en donde el promovente tenga su domicilio fiscal y, por recibidas, en el lugar de la sede de la Sala Regional a la que corresponda conocer del juicio por razón de territorio. Tratándose de un día inhábil se tendrán por presentadas el día hábil siguiente.

El Sistema de Justicia en Línea emitirá un acuse de recibo señalando la fecha y la hora de recibido, cuando reciba por vía electrónica cualquier promoción de las partes.

Dicho Sistema, según lo establecen los Lineamientos de marras, funcionará de acuerdo con la hora oficial mexicana, que comprende los tres husos horarios que cu- 
bren la República Mexicana, esto es, representando las horas locales del país.

Respecto a los husos horarios que rigen en nuestro país, debe decirse que el 29 de diciembre de 2001, se publicó en el Diario Oficial de la Federación la Ley del Sistema de Horario en los Estados Unidos Mexicanos, la cual, en su artículo $3^{\circ}$, establece para el territorio nacional las siguientes zonas:

I. Zona Centro: Referida al meridiano 90 grados al oeste de Greenwich y que comprende la mayor parte del territorio nacional, con la salvedad de lo establecido en los numerales II, III y IV del citado artículo 3;

II.Zona Pacífico: Referida al meridiano 105 oeste y que comprende los territorios de los estados de Baja California Sur; Chihuahua; Nayarit, con excepción del municipio de Bahía de Banderas, el cual se regirá conforme a la fracción anterior en lo relativo a la Zona Centro; Sinaloa y Sonora;

III. Zona Noroeste: Referida al meridiano 120 oeste y que comprende el territorio del Estado de Baja California, y

IV. Las islas, arrecifes y cayos quedarán comprendidos dentro del meridiano al cual corresponda su situación geográfica y de acuerdo a los instrumentos de derecho internacional aceptados.

\section{IX.Actuaciones en el juicio en línea}

Cualquier actuación en el juicio en línea se efectuará a través del Sistema de Justicia en Línea del Tribunal, en términos del Capítulo X, Título II, de la ley de la materia. Dichas actuaciones serán validadas con las firmas electrónicas avanzadas de los Magistrados y Secretarios de Acuerdos que den fe según corresponda.

\section{Pruebas}

En el juicio contencioso administrativo federal, la prueba que más ofrecen los justiciables es la documental; por ello, el artículo 58-K de la Ley Federal de Procedimiento Contencioso Administrativo prevé reglas específicas para su ofrecimiento cuando el juicio se tramite a través del Sistema de Justicia en Línea.

En efecto, el citado precepto legal dispone que los documentos que las partes ofrezcan como prueba, incluido el expediente administrativo a que se refiere el artículo 14, fracción $\mathrm{V}$, de dicha ley, deberán exhibirlos de forma legible a través del Sistema de Justicia en Línea, para lo cual, claro está, el oferente deberá digitalizarlos o escanearlos.

A este respecto, el artículo 36 de los referidos Lineamientos establece que cualquier documento electrónico o digitalizado, que obre en el expediente electrónico o sea ofrecido por las partes en el juicio, deberá cumplir con las características de ser accesible, de fácil manejo, inalterable y sin restricciones de copiado del texto o de cualquier contenido, impresión y consulta, así como las demás características precisadas en el Anexo Único de dichos Lineamientos.

En el referido Anexo Único se señala que las características mínimas que deberán reunir los documentos electrónicos que se utilicen dentro del Sistema de Justicia en Línea, ya sea porque las partes los ofrezcan como 
prueba, o porque formen parte del expediente electrónico, son las siguientes:

I. Los documentos digitalizados o escaneados deberán contar con una resolución óptica en rangos de entre 100 y $600 \mathrm{dpi}$, con la posibilidad de ajustar la resolución en caso necesario. Para ello se recomienda generar la salida del documento digitalizado o escaneado en formato PDF a 200 dpi y 256 colores, preferentemente, además de contar con la opción de "solo lectura" y permitir la selección del texto.

II. Para los archivos de "tipo imagen" serán aceptados los siguientes formatos: .jpg, .jpeg, .tif, .bmp, .png, .jpe, .jfif, .gif, .dib que pueden ser abiertos por la mayoría de las herramientas de visualización.

III. Los documentos asociados a videos y audio, podrán presentarse en alguno de los formatos siguientes: .avi, .flv, .mp4, .wmv, DVD-video (video); .mp3, .wmv, audio CD, DVD-audio, .wma, .mpg (audio).

IV. Los documentos elaborados con herramientas de productividad para oficina, de la suite de Microsoft se aceptarán en Word, Excel y PowerPoint en sus versiones 97, 2000, 2002, 2003, 2007 y 2010; también se aceptarán otras suites, como Works 6.0, $7.0,8.0$ y 9.0 ; WordPerfect 5.0 y 6.0 ; de igual manera formatos abiertos emitidos por Staroffice, Openoffice, Lotus Symphony, entre otros: .odf.

v. Específicamente, para documentos que contengan datos o información generados por otras herramientas, también se aceptarán los siguientes formatos: .xml, rtf, .txt, .html, htm, .mht, .mhtml.
Otra obligación a cargo del oferente con respecto a documentos digitales es la relativa a manifestar la naturaleza de los mismos, por lo cual deberá especificar si la reproducción digital corresponde a una copia simple, una copia certificada o al original y tratándose de esta última, si tiene o no firma autógrafa. Esa manifestación, señala la ley de la materia, deberán hacerla los particulares bajo protesta de decir verdad, y su omisión presume en perjuicio solo del promovente, que el documento digitalizado corresponde a una copia simple.

Lo anterior, desde nuestro punto de vista, es violatorio del principio de igualdad procesal, puesto que solo se exige a los particulares, y no a las autoridades administrativas, que realicen la manifestación a que se ha hecho alusión, lo cual se considera trascendente si se toma en cuenta que cualquiera de las partes en el juicio puede faltar a la verdad, al manifestar la naturaleza de los documentos digitales y, por ello, incurrir en el delito de falsedad en declaraciones judiciales que prevé el artículo 247, fracción I, del Código Penal Federal; circunstancia que no sucedería en el caso de las autoridades administrativas, dado que, como hemos visto, estas no tienen la obligación de formular la susodicha manifestación.

Es importante señalar que las pruebas documentales (digitales) que las partes ofrezcan y exhiban en el juicio, tendrán el mismo valor probatorio que su constancia física, siempre y cuando se observen las disposiciones contenidas en la Ley Federal de Procedimiento Contencioso Administrativo $\mathrm{y}$ en los acuerdos normativos (Acuerdo E/ JGA/16/2011) que emitan los órganos del Tribunal Federal de Justicia Administrativa 
para asegurar la autenticidad de la información, así como de su transmisión, recepción, validación y notificación.

No se omite señalar que si bien la información que envíen los usuarios del Sistema de Justicia en Línea, contenida en texto, imagen, audio o video, podría encontrarse infectada con algún tipo de virus informático, el artículo 26 del Acuerdo E/JGA/16/2011 dispone que a fin de asegurar la integridad del sistema, este contará con un servicio de antivirus para la revisión de los archivos electrónicos que se generen, envíen y reciban a través del mismo.

Por lo cual, los usuarios internos, en caso de que adviertan que un archivo o documento electrónico está infectado por un virus u otro software maligno, se abstendrán de abrirlo, ejecutarlo, copiarlo, difundirlo o transmitirlo por cualquier medio dentro del Sistema de Justicia en Línea, y el personal de la Unidad de Administración procederá a realizar una certificación de las circunstancias en las que se recibió el archivo o documento y levantará acta administrativa.

Si el archivo o documento infectado con virus es necesario para la sustanciación del juicio en línea, se le enviará al usuario externo que lo haya remitido un correo electrónico, a través del cual se le hará saber sobre el archivo o documento infectado y se le requerirá, para que en el plazo de tres días hábiles envíe nuevamente el archivo o documento limpio de virus o software maligno, apercibimiento de que, de no hacerlo, no será considerado en el juicio correspondiente. La misma regla se aplica tratándose de archivos o documentos electrónicos que estén dañados o por cualquier otra causa no pueda comprobarse su contenido.

\section{Pruebas diversas a las documentales}

El numeral 58-L de la Ley Federal de Procedimiento Contencioso Administrativo señala que tratándose de pruebas diversas a las documentales, "los instrumentos en los que se haga constar la existencia de dichas pruebas se integrarán al expediente electrónico"; para tal efecto, el "Secretario de Acuerdos del Tribunal deberá digitalizar las constancias relativas y proceder a la certificación de su cotejo con los originales físicos, así como a garantizar el resguardo de los originales y de los bienes materiales que en su caso hubieren sido objeto de prueba". Este supuesto evidentemente se refiere a pruebas como la pericial, la testimonial y la inspección judicial.

En lo atinente al desahogo de pruebas no documentales que requieran la generación de un acta, como es el caso de las señaladas en el párrafo anterior, el artículo 39 del Acuerdo E/JGA/16/2011 establece que cuando en un juicio en línea deban desahogarse pruebas de esa naturaleza y sea necesario generar "un acta, ésta se asentará en documento impreso, el cual deberá contener la firma autógrafa de quienes en ella intervengan, así como las del Magistrado Instructor y del Secretario de Acuerdos" y, hecho ello, este último procederá de la siguiente manera:

\section{A digitalizar, certificar y resguardar el acta en términos de los artículos 42, 43 y 44 del mencionado Acuerdo y, \\ II. Incluir el acta en el expediente electró- nico correspondiente.}


En el segundo párrafo del precepto legal que se analiza (58-L de la ley de la materia) se señala literalmente lo siguiente: "Para el caso de pruebas diversas a las documentales, éstas deberán ofrecerse en la demanda y ser presentadas a la Sala que esté conociendo del asunto, en la misma fecha en la que se registre en el Sistema de Justicia en Línea del Tribunal la promoción correspondiente a su ofrecimiento, haciendo constar su recepción por vía electrónica".

La forma como está redactado el párrafo transcrito da lugar a confusión, en razón de que “(...) pareciera, que por ejemplo, en el caso de la pericial, el dictamen debe presentarse junto con la demanda, lo cual es improcedente, considerando que previamente debió tomarse la protesta al perito designado. Igualmente dicha situación puede presentarse en el caso de la prueba testimonial, toda vez que es imposible que se presente el testimonio de los testigos junto con la demanda" (Reyes Altamirano, 2011, p. 54).

Por lo cual, es posible concluir que no obstante que el párrafo de que se trata señale textualmente que "Para el caso de pruebas diversas a las documentales", en estas no pueden ni deben considerarse incluidas la pericial, la testimonial y la inspección judicial. En esa virtud, consideramos que dicho párrafo se refiere más bien a pruebas materiales o físicas, como podrían ser, por ejemplo, alguna sustancia o mercancía en materia aduanera o algún diseño industrial de los regulados por la Ley de la Propiedad Industrial.

Otro aspecto relevante es el relativo a que ese tipo de pruebas (físicas o materiales) deben ofrecerse en la demanda y ser pre- sentadas a la Sala que esté conociendo del asunto, en la misma fecha en la que se registre en el Sistema de Justicia en Línea del Tribunal la promoción correspondiente a su ofrecimiento, haciendo constar su recepción por vía electrónica; lo cual estimamos que generará gastos extraordinarios al justiciable, toda vez que, si bien, para presentar su demanda en línea no tendrá que trasladarse al recinto del Tribunal, pues lo hará a través del Sistema de Justicia en Línea, en Internet, en caso de que ofrezca ese tipo de pruebas (materiales o físicas) sí tendría que hacerlo, dado que tiene la obligación de presentarlas a la Sala que esté conociendo del asunto, en la misma fecha en la que se registre en el citado Sistema la promoción correspondiente a su ofrecimiento, pero dicho traslado tendría que realizarlo al Distrito Federal, ya que por el momento y después de más de cinco años de haberse implementado el juicio en línea, en el país solo existen dos salas que conocen del mismo, a saber, la Sala Especializada en Materia de Propiedad Intelectual y la Sala Especializada en Juicios en Línea, ambas con sede en la Ciudad de México.

\section{Copias para traslado en el caso de terceros interesados}

Si el juicio se tramita a través del Sistema de Justicia en Línea, no es necesario que las partes exhiban copias para correr los traslados de ley, a menos que existan terceros interesados, en cuyo caso el demandante deberá exhibirlos junto con sus respectivos anexos.

Respecto de los terceros interesados, es conveniente mencionar que si estos deciden apersonarse en el juicio, en el escrito en que lo hagan deberán precisar si es su deseo que el mismo se continúe substanciando en lí- 
nea y señalar, en ese supuesto, su dirección de correo electrónico. Si su decisión es en sentido negativo, el Tribunal decidirá lo conducente a efecto de que se digitalicen o escaneen los documentos que dichos terceros presenten, para que se prosiga con la instrucción del juicio en línea con respecto a las demás partes, y a la vez, se impriman y certifiquen las constancias de las actuaciones y documentación electrónica, a fin de que se integre el expediente de los terceros en un juicio en la vía tradicional.

Lo anterior encuadra perfectamente en lo que se ha denominado juicio híbrido (la ley no señala está denominación; sin embargo, el propio Tribunal Federal de Justicia Administrativa ha optado por llamarle así); un juicio de tal naturaleza es aquel que "(...) se tramitará en línea para una parte (la autoridad como actora, por citar un ejemplo) mientras que para el particular demandado será tradicional si decide comparecer por la vía tradicional en este caso, debiendo el Tribunal imprimir y certificar las constancias digitales que una de las partes presente, y digitalizar y certificar los documentos que la otra parte presente en oficialía de partes" (Irigoyen, Urdapilleta, op.cit., nota 3 , pp. 7 y 8 ).

\section{Notificaciones}

En términos de lo dispuesto en el artículo 58-N de la Ley Federal de Procedimiento Contencioso Administrativo, las notificaciones que se practiquen y se dentro del juicio en línea se efectuarán conforme a lo siguiente:

I. Todas las actuaciones y resoluciones que conforme a las disposiciones de esa ley deban notificarse en forma personal, mediante correo certificado con acuse de recibo, o por oficio, se deberán realizar a través del Sistema de Justicia en Línea.

II. El actuario deberá elaborar la minuta electrónica en la que precise la actuación o resolución a notificar, así como los documentos que se adjunten a la misma. Dicha minuta, que contendrá la firma electrónica avanzada del actuario, será ingresada al Sistema de Justicia en Línea junto con la actuación o resolución respectiva y los documentos adjuntos.

III. El actuario enviará a la dirección de correo electrónico de la o las partes a notificar, un aviso haciéndoles saber que se ha dictado una actuación o resolución en el expediente electrónico, la cual estará disponible en el aludido sistema.

IV. El sistema de justicia en línea del tribunal registrará la fecha y hora en que se efectúe el envío señalado en la fracción anterior.

V. Se tendrá como legalmente practicada la notificación conforme a lo señalado en las fracciones anteriores, cuando el Sistema de Justicia en Línea genere el acuse de recibo electrónico donde conste la fecha y hora en que la o las partes notificadas ingresaron al expediente electrónico, lo que deberá suceder dentro del plazo de tres días hábiles siguientes a la fecha de envío del aviso a la dirección de correo electrónico de la o las partes a notificar.

VI. En caso de que el Sistema de Justicia en Línea no genere el acuse de recibo donde conste que la notificación fue realizada, la misma se efectuará mediante lista y por 
boletín procesal (el único boletín que existe actualmente en la ley es el jurisdiccional, por lo que en este caso hay un error de técnica legislativa), al cuarto día hábil contado a partir de la fecha de envío del correo electrónico, fecha en que se tendrá por legalmente notificada la o las partes.

\section{Horas hábiles}

De conformidad con lo previsto en el artículo 58-O de la ley de la materia, en el juicio en línea son hábiles las veinticuatro horas de los días en que se encuentren abiertas al público las oficinas de las Salas del Tribunal Federal de Justicia Administrativa.

Con fundamento en lo dispuesto en el artículo 65 de la Ley Orgánica del Tribunal Federal de Justicia Administrativa, el Pleno General de dicho órgano de justicia tiene la facultad de suspender las labores generales del Tribunal y no correrán los plazos.

\section{Obligaciones de las autoridades administrativas}

A partir de la entrada en vigor del Decreto por el que se reforman y adicionan diversas disposiciones de la Ley Federal de Procedimiento Contencioso Administrativo y de la Ley Orgánica del Tribunal Federal de Justicia Fiscal y Administrativa, publicado en el Diario Oficial de la Federación el 12 de junio de 2009 (decreto que crea el juicio en línea), se estableció una nueva obligación a cargo de todas aquellas autoridades administrativas cuyos actos sean susceptibles de impugnarse ante el Tribunal Federal de Justicia Fiscal y Administrativa, consistente en registrar en la Secretaría General de Acuerdos o ante la Presidencia de las Salas
Regionales del aludido Tribunal, según corresponda, la dirección de correo electrónico institucional, así como el domicilio oficial de las unidades administrativas a las que corresponda su representación en los juicios contencioso administrativos, para el efecto de emplazarlas electrónicamente a juicio en aquellos casos en los que tengan el carácter de autoridad demandada.

En el supuesto de que dichas autoridades no cumplan con la citada obligación, dispone la ley que todas las notificaciones que deban hacerse, incluyendo el emplazamiento, se harán a través del boletín procesal (el único boletín que existe actualmente es el boletín jurisdiccional, por lo que en este caso hay un error de técnica legislativa), hasta que se cumpla con dicha formalidad.

\section{Inaplicación de las reglas del juicio en línea en el recurso de revisión y en el juicio de amparo}

En términos de lo dispuesto en el artículo 58-Q de la Ley Federal de Procedimiento Contencioso Administrativo, las reglas del juicio en línea no son aplicables para la presentación y trámite de los recursos de revisión y juicios de amparo que se promuevan contra las actuaciones y resoluciones derivadas del mismo.

Lo anterior se robustece con lo previsto en el artículo 25 del Acuerdo E/JGA/16/2011, que dispone que los usuarios del portal del referido Tribunal y del Sistema de Justicia en Línea deberán abstenerse de utilizarlo para cargar, anunciar o enviar cualquier contenido con propósitos diversos a la promoción y sustanciación de un juicio contencioso administrativo federal. 
Ilustra lo anterior la siguiente tesis aislada:

Época: Décima Época

Registro: 2000893

Instancia: Tribunales Colegiados de Circuito

Tipo de Tesis: Aislada

Fuente: Semanario Judicial de la Federación y su Gaceta

Libro VIII, Mayo de 2012, Tomo 2

Materia(s): Administrativa

Tesis: I.7o.A.26 A (10a.)

Página: 2105

REVISIÓN FISCAL. DEBE TENERSE POR NO INTERPUESTO DICHO RECURSO, TRATÁNDOSE DE SENTENCIAS EMITIDAS POR LA SALA ESPECIALIZADA EN JUICIOS EN LÍNEA DEL TRIBUNAL FEDERAL DE JUSTICIA FISCAL Y ADMINISTRATIVA, SI LA AUTORIDAD PRESENTA EL ESCRITO RELATIVO A TRAVÉS DEL SISTEMA QUE RIGE ESE TIPO DE PROCEDIMIENTOS. El artículo 58-Q de la Ley Federal de Procedimiento Contencioso Administrativo establece que para la presentación y trámite de los recursos de revisión y juicios de amparo que se promuevan contra las actuaciones y resoluciones derivadas del juicio en línea, no será aplicable el capítulo $\mathrm{X}$ del título II de dicho ordenamiento -en el que se establecen las reglas para ese tipo de procedimientos-, circunstancia que se confirma con el numeral 25 de los Lineamientos técnicos y formales para la sustanciación del juicio en línea aprobados por la Junta de Gobierno y
Administración del Tribunal Federal de Justicia Fiscal y Administrativa en el Acuerdo E/JGA/16/2011, publicado en el Diario Oficial de la Federación el 4 de mayo de 2011, el cual prevé que los usuarios del portal del citado tribunal deberán abstenerse de utilizar el sistema de juicios en línea para cargar, anunciar o enviar cualquier contenido con propósitos diversos a la promoción y sustanciación de un juicio contencioso administrativo federal. En ese contexto, se colige que, tratándose de sentencias emitidas por la Sala Especializada en Juicios en Línea, la presentación y trámite del recurso de revisión fiscal se rigen por los artículos 104, fracción III, de la Constitución Política de los Estados Unidos Mexicanos, 63 de la Ley Federal de Procedimiento Contencioso Administrativo y 88 de la Ley de Amparo, los cuales exigen, entre otros requisitos, que se presente por escrito ante la Oficialía de Partes Común del Tribunal Federal de Justicia Fiscal y Administrativa con sede en el Distrito Federal, con independencia del domicilio de las partes, ya que la indicada Sala tiene su sede en dicha demarcación territorial, tal como lo prevé el precepto legal 23, fracción II, del reglamento interior del mencionado órgano jurisdiccional y, además, la inconforme deberá exhibir sendas copias para el expediente y para cada una de las otras partes. Por tanto, debe tenerse por no interpuesto dicho recurso si la autoridad presenta el escrito relativo a través del sistema de justicia en línea del referido tribunal.

En razón de lo anterior, los servidores públicos jurisdiccionales del Tribunal Federal de Justicia Administrativa tienen la obligación de imprimir el archivo del expediente electrónico y certificar las constancias del juicio que deban ser remitidos a los Juzga- 
dos de Distrito y Tribunales Colegiados de Circuito, cuando se impugnen resoluciones de los juicios correspondientes a su mesa.

No obstante ello, en aquellos casos en que lo solicite el Juzgado de Distrito o el Tribunal Colegiado, se podrá remitir la información a través de medios electrónicos.

$\mathrm{Al}$ respecto, es importante mencionar que la nueva de Ley de Amparo publicada en el Diario Oficial de la Federación el 2 de abril de 2013, ya contempla la posibilidad de que los particulares acudan a la justicia federal a promover juicios de amparo por medios electrónicos.

En atención a ello, el 8 de julio de 2013 se publicó en el referido Diario, el Acuerdo General Conjunto número 1/2013 de la Suprema Corte de Justicia de la Nación, del Tribunal Electoral del Poder Judicial de la Federación y del Consejo de la Judicatura Federal, relativo a la Firma Electrónica Certificada del Poder Judicial de la Federación (FIREL) y al expediente electrónico. En dicho Acuerdo, se regulan las bases para la creación, otorgamiento y uso de la firma electrónica certificada del Poder Judicial de la Federación, así como la integración, consulta y almacenamiento del expediente electrónico en los órganos administrativos y jurisdiccionales del Poder Judicial de la Federación.

Los beneficios para el justiciable de contar con la firma electrónica certificada del Poder Judicial de la Federación, son los siguientes:
- Podrá promover demandas de amparo por medios electrónicos los 365 días del año.

- Podrá consultar por medios electrónicos los expedientes de los juicios de amparo en los que sea parte.

- Tendrá la opción de promover por vía impresa o electrónica en los juicios de amparo en los que sea parte.

- Por medios electrónicos podrá promover demandas de amparo e interponer recursos sin necesidad de acompañar copias de traslado para las demás partes.

- Podrá recibir notificaciones por vía electrónica si así lo solicita.

- Las demandas de amparo, recursos y diversas promociones que presente con su FIREL producirán los mismos efectos jurídicos que las suscritas con su firma autógrafa ${ }^{4}$.

\section{Interrupción del funcionamiento del sistema de justicia en línea}

El numeral 58-S de la ley de la materia establece que "cuando por caso fortuito, fuerza mayor o por fallas técnicas se interrumpa el funcionamiento del Sistema de Justicia en Línea, haciendo imposible el cumplimiento de los plazos establecidos en la ley, las partes deberán dar aviso a la Sala correspondiente en la misma promoción sujeta a término, la cual pedirá un reporte al titular de la unidad administrativa del Tribunal responsable de

${ }^{4}$ https://www.scjn.gob.mx/Lists/BannerVerticalV2/Attachments/54/FIREL_Justiciables_17SEP.
pdf. Consultado el 25 de septiembre de 2016 . 
la administración del Sistema sobre la existencia de la interrupción del servicio. En el supuesto de que el reporte de mérito determine que existió la interrupción en el sistema, deberá indicar la causa y el tiempo de dicha interrupción, señalando la fecha y hora de inicio y término de la misma, a fin de que los plazos procesales se suspendan únicamente el tiempo que duró la interrupción. Para ello, la Sala hará constar esta situación mediante acuerdo en el expediente electrónico y, tomando en consideración el tiempo de la interrupción, realizará el cómputo correspondiente, a efecto de determinar si hubo o no incumplimiento de los plazos legales".

A este respecto, el artículo 37 del Acuerdo E/JGA/16/2011, establece que "En atención a lo dispuesto en el artículo 58-S de la Ley, en caso de que la Unidad de Administración reporte la interrupción en el funcionamiento del Sistema por caso fortuito, fuerza mayor o falla técnica, la Sala considerará el tiempo de la interrupción y suspenderá los plazos únicamente respecto de aquellas promociones sujetas a término por ese mismo lapso o bien hasta el día hábil siguiente en que el Sistema haya sido restablecido, a efecto de determinar la oportunidad de dichas promociones".

Nótese la evidente contradicción que existe entre el contenido del artículo 58-S de la Ley Federal de Procedimiento Contencioso Administrativo y el artículo 37 del Acuerdo a que se ha hecho alusión, puesto que “(...) para el primero 'los plazos se suspenderán, únicamente, el tiempo que dure la interrupción del Sistema', mientras que el segundo dispone que solo "se suspenderá los plazos únicamente de aquellas promociones sujetas a término por ese mismo lapso o bien hasta el día hábil siguiente en que el Sistema haya sido restablecido" (Reyes Altamirano, op. cit., nota 7, p. 26).

\section{La acumulación de juicios sustanciados en línea y en la vía tradicional}

El legislador federal, previendo la posibilidad de que procediera la acumulación de juicios cuando se actualizan los supuestos previstos en el artículo 31 de la Ley Federal de Procedimiento Contencioso Administrativo, y de que estos se estén sustanciando en la vía tradicional y en línea, dispuso en el último párrafo del numeral en cita que, cuando ello acontezca, el Magistrado Instructor requerirá a las partes relativas al juicio en la vía tradicional para que dentro del plazo de tres días manifiesten si optan por substanciar el juicio en línea; en caso de que no ejerza su opción, se tramitará el juicio en la vía tradicional.

Además de lo anterior, el artículo 40 del Acuerdo E/JGA/16/2011 señala que en caso de que proceda la acumulación de juicios sustanciados en línea y en la vía tradicional, y los particulares que sean parte de este último rechacen la posibilidad de que se tramite en línea, se estará a lo siguiente:

I. Las partes que eligieron el juicio en línea, también podrán consultar el expediente del juicio tramitado en la vía tradicional, para lo cual deberán acudir al local de la Sala en que se encuentre radicado, $y$

II. Las partes que eligieron la vía tradicional, también podrán consultar el expediente electrónico del juicio sustanciado en línea, previa obtención de su clave de acceso y contraseña en los términos previstos en el Acuerdo de marras. 


\section{Bibliografía}

Jiménez Illescas, Juan Manuel (2009). El juicio en Línea. Procedimiento Contencioso Administrativo Federal, México, Dofiscal.

Irigoyen Urdapilleta, César Octavio (2012). “Notas Generales del Juicio en Línea”, en Revista Digital Praxis de la Justicia Fiscal y Administrativa. México, $n^{\circ} 10$ (Año IV) pp.6, en http://www.tfjfa.gob.mx/investigaciones/ pdf/notasgeneralesdeljuicioen.pdf. Consultado el 10 de junio de 2014.

Reyes Altamirano, Rigoberto (2011). Juicio en línea y juicio sumario en materia fiscal. Guía para su aplicación práctica. México: Tax Editores Unidos.

\section{Leyes}

Constitución Política de los Estados Unidos Mexicanos.

Convención Americana sobre Derechos Humanos "Pacto de San José Costa Rica".

Ley de Amparo, Reglamentaria de los Artículos 103 y 107 de la Constitución Política de los Estados Unidos Mexicanos.

Ley Federal de Procedimiento Contencioso Administrativo.

Ley Orgánica del Tribunal Federal de Justicia Administrativa.

Lineamientos Técnicos y Formales para la Sustanciación del juicio en línea.

\section{Electrónicas}

http://www.scjn.gob.mx/

https://www.scjn.gob.mx/Lists/BannerVerticalV2/Attachments/54/FIREL_Justiciables_17SEP.pdf, consultado el 25 de septiembre de 2016.

http://www.tfjfa.gb.mx

\section{Decretos}

Iniciativa de decreto por el que se reforman, adicionan y derogan diversas disposiciones de la Ley Federal de Procedimiento Contencioso Administrativo y de la Ley Orgánica del Tribunal Federal de Justicia Fiscal y Administrativa, publicado en el Diario Oficial de la Federación del día 12 de junio de 2009.

Iniciativa de decreto por el que se reforman, adicionan y derogan diversas disposiciones de la Ley Federal de Procedimiento Contencioso Administrativo y de la Ley Orgánica del Tribunal Federal de Justicia Fiscal y Administrativa, publicado en el Diario Oficial de la Federación del día 10 de diciembre de 2010. 